\title{
Inducció electromagnètica
}

\author{
Lluís Nadal i Balandras $\bowtie$ \\ Centre de Documentació $i$ Experimentació de Ciències (CESIRE - CDEC)
}

Es proposen diversos experiments per mostrar de quina manera l'energia mecànica es pot transformar en elèctrica i l'elèctrica en mecànica, estudiant quins factors que hi intervenen.

Paraules clau: inducció magnètica, camp magnètic, flux magnètic, línies de força, energia mecànica, energia elèctrica, llei de Faraday, generació de corrent elèctric

\section{Fonament teòric}

El flux magnètic sobre una superfície es pot definir com el nombre de línies de força que travessen la superfície, suposant que hi ha tantes línies per metre quadrat d'una superfície, col-locada perpendicularment, com indica el valor de la inducció magnètica, $\mathbf{B}$. Les línies de força es poden visualitzar amb llimadures de ferro i un imant (fig. 1).

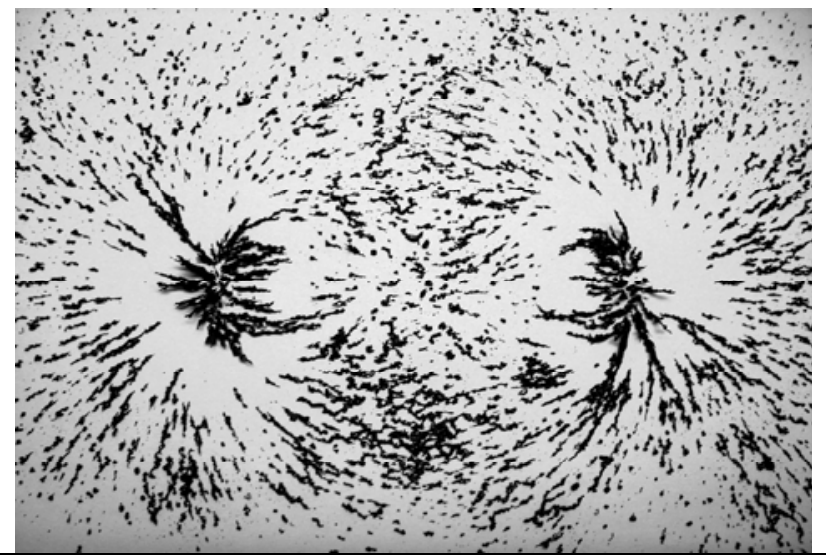

Figura 1. Llimadures de ferro properes a un imant.

Quan circula un corrent per un circuit s'origina un camp magnètic. Llavors, un camp magnètic en un circuit... també originarà un corrent?

Efectivament es produeix un corrent només si el camp magnètic és variable 0 , d'una manera més general, sempre que hi hagi variació del flux magnètic en el circuit. Fer variar el nombre de línies de força que travessen un circuit elèctric es pot aconseguir de diverses maneres: modificant la distància
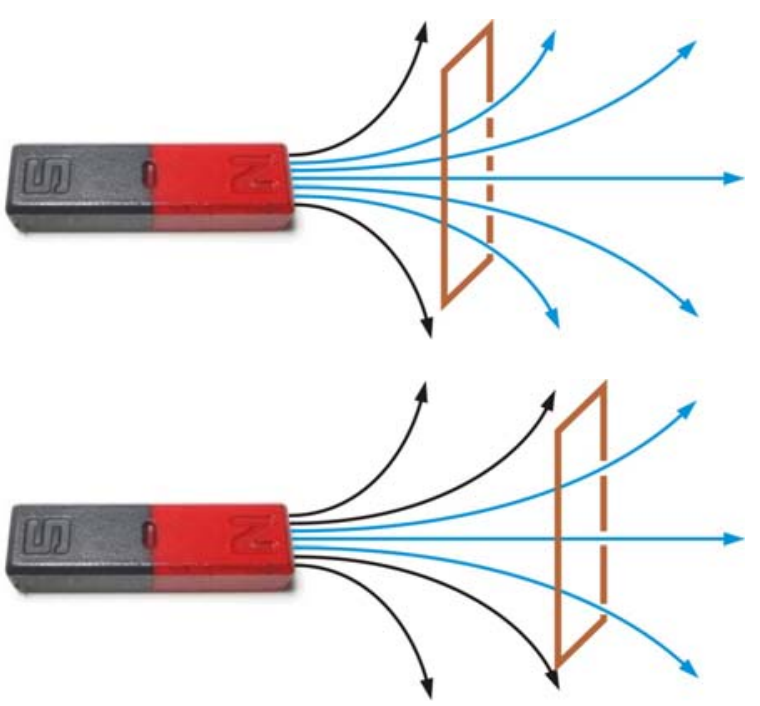

Figura 2. Allunyant l'imant del circuit tancat, disminueix el flux magnètic que el travessa.

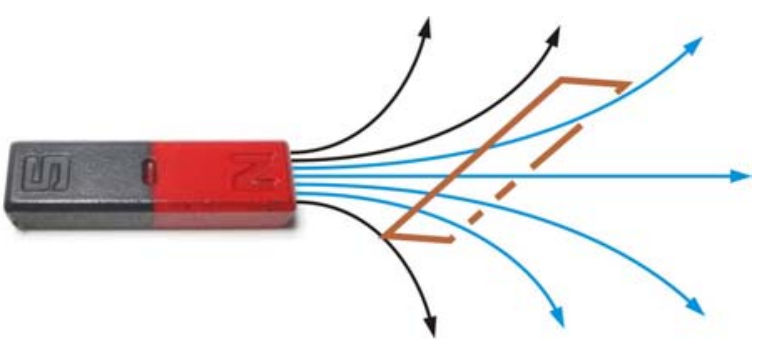

Figura 3. Variant l'angle entre el circuit i les línies de camp també s'aconsegueix variar el flux magnètic. 
entre el circuit i l'imant (fig. 2) o bé la seva posició relativa (fig. 3).

Així, doncs, hi ha tres possibilitats per produir un corrent induït:

a) El camp varia amb el temps

b) El camp és constant però hi ha moviment relatiu entre ell i el circuit

c) Varia la superfície del circuit

En general, la força electromotriu induïda, E, ve donada per la llei de Faraday:

$$
\mathrm{E}=-\mathrm{N} d \Phi / \mathrm{dt}
$$

on $N$ és el nombre d'espires i $\Phi$ el flux magnètic.

\section{Mètode operatiu}

Per realitzar els següents experiments necessitareu:

- 2 imants

- 3 bobines de 500 espires

- agulla indicadora de l'amperímetre

- motor

- pila de 4,5 V

- interruptor

- brúixola

- nucli de ferro

- cables de connexió

\section{Camp produït per una bobina}

Feu el muntatge de la figura 4, connectant el positiu al connector roig de la bobina i poseu-la en posició horitzontal a prop de la brúixola. Si veiem la fletxa que té dibuixada, els connectors cap endavant i el roig al positiu, el corrent circularà en sentit oposat a les busques del rellotge.

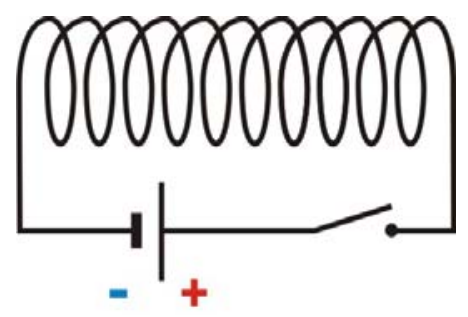

Figura 4. Diagrama del circuit a construir, amb una bobina, pila i interruptor.
Tanqueu l'interruptor un instant i observeu quin pol de la brúixola resulta atret.

Repetiu-ho canviant la polaritat de les connexions amb la pila.

Relacioneu el sentit del corrent amb el pol que es forma a la bobina. És útil posar les observacions en forma de taula, per exemple:

\begin{tabular}{|l|l|l|}
\hline $\begin{array}{l}\text { Sentit del corrent } \\
\text { en la bobina }\end{array}$ & $\begin{array}{l}\text { Pol de la brúixola } \\
\text { que és atret }\end{array}$ & $\begin{array}{l}\text { Pol format en la } \\
\text { cara de la bobina } \\
\text { que mira a l'imant }\end{array}$ \\
\hline & & \\
\hline & & \\
\hline
\end{tabular}

Figura 5. Model de taula per organitzar els resultats de les observacions.

\section{Inducció entre un imant i una bobina (camp constant, posició variable)}

Connecteu els pols de mateix color de la bobina i de l'amperímetre tal com es veu a la fig. 6, de tal manera que les fletxes que porten dibuixades quedin a la part superior i els connectors de cara endavant.

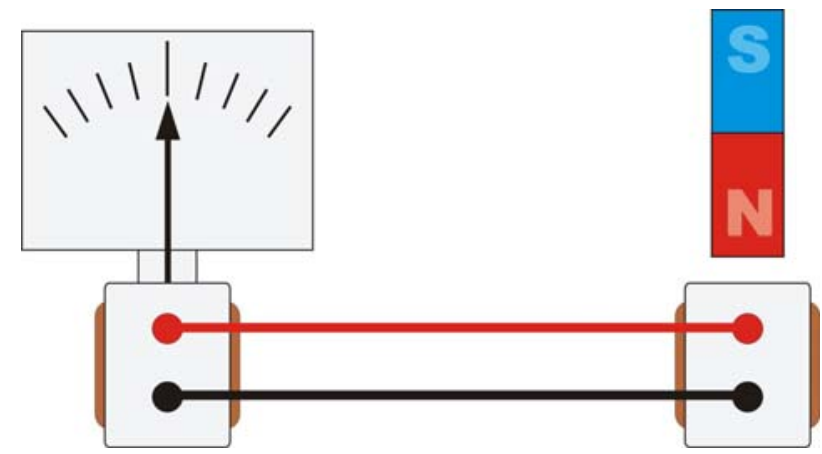

Figura 6. Diagrama del muntatge que cal fer.

En aquestes condicions el sentit dels bobinats és contrari a les busques del rellotge a partir del connector roig. El pol nord de l'imant sol ser el roig.

A continuació observeu cap a on es desvia l'amperímetre en els casos següents:

a) Introduint un pol nord en la bobina

b) Deixant l'imant quiet 
c) Traient el pol nord de la bobina

d) Introduint-hi un pol sud

e) Deixant l'imant quiet

f) Traient-ne el pol sud

Ara mireu si el següent afecta els resultats:

g) Té algun efecte la rapidesa amb què es mou l'imant?

h) Canvia alguna cosa si deixeu l'imant quiet i moveu la bobina?

A partir de la desviació de l'amperímetre i dels resultats de l'experiment número 1 , deduïu:

i) Quin era el sentit del corrent a la bobina?

j) Quin pol magnètic s'ha format en la cara de la bobina que mira a l'imant?

k) Intenteu resumir les observacions, posant-les juntament amb les deduccions en forma de taula.

\section{Inducció entre dues bobines (camp variable)}

Utilitzant part del muntatge anterior, afegim una altra bobina connectada a una altra i a un interruptor. Posem les bobines una a continuació de l'altra (fig. 7) i el nucli de ferro a l'interior de totes dues.

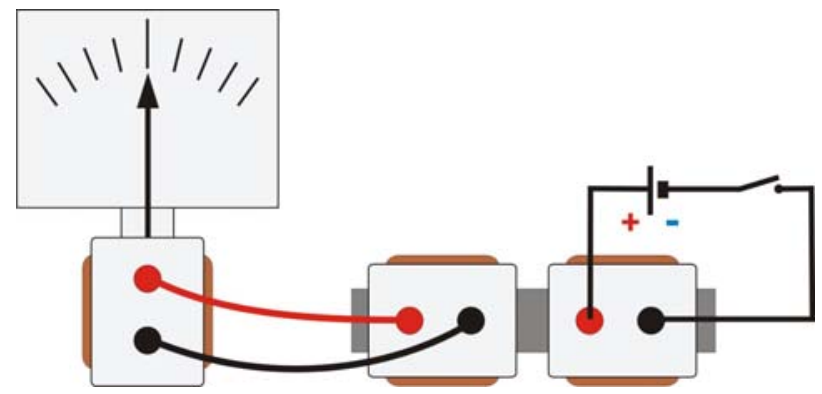

Figura 7. Muntatge.

Observeu la desviació de l'amperímetre en els casos següents:

a) En el moment que tanqueu l'interruptor

b) Amb l'interruptor tancat (circuit connectat)

c) En el moment que obrim l'interruptor

d) Amb l'interruptor obert (circuit desconnectat)
I contesteu també:

e) Té algun efecte la rapidesa en connectar i desconnectar?

f) Què canvia quan s'inverteix la polaritat de la pila?

g) Quin pol es forma en la cara de la segona bobina que mira a la primera?

h) Els resultats coincideixen amb els de l'experiment número 2?

\section{Aplicació a la generació de corrent}

Gairebé tot el corrent que s'utilitza és produït mitjançant corrents induïts. Normalment s'utilitza en forma de corrent altern i es produeix utilitzant alternadors. També es pot produir corrent continu per mitjà de dinamos, però per una sèrie de raons resulta menys pràctic.

El motor del qual disposem es pot fer funcionar com a dinamo o com a alternador, desplaçant uns contactes (escombretes) que freguen amb un cilindre. Si els posem en el centre del cilindre funciona com a dinamo, mentre que si els posem un a cada extrem, funciona com a alternador: sabries trobar-hi una explicació?

Connecteu el motor amb l'amperímetre i observeu la desviació en cada cas. Si funciona com a dinamo:

a) Feu girar el motor en el sentit del rellotge

b) Feu-lo girar en sentit contrari al del rellotge

c) Hi té alguna influència la velocitat de rotació?

Seguidament munteu-lo com a alternador i repetiu a, b i c.

Finalment, comproveu el funcionament com a motor connectant-li una o dues piles de 4,5 V.

Tenim un aparell que pot convertir l'energia elèctrica en mecànica i l'energia mecànica en elèctrica. És interessant veure els corrents induïts dels experiments 2 i 3 a l'oscil.loscopi. Per exemple, introduint i traient l'imant de dins de la bobina es pot visualitzar el corrent altern.

Aquests experiments formen part del fons del CESIRE - CDEC (Centre de Documentació i Experimentació de ciències) del Departament d'Ensenyament, Generalitat de Catalunya. 